\title{
Buttock pain after sacrospinous hysteropexy
}

\author{
Christian Wallner
}

Received: 10 March 2008 / Accepted: 19 April 2008 / Published online: 21 June 2008

(C) The Author(s) 2008

\section{Dear Editor:}

With great interest, I read the recent publication of Dietz et al. [1] in your journal. The authors describe that buttock pain occurred post-operatively in $\sim 18 \%$ of patients undergoing sacrospinous hysteropexy for pelvic organ prolapse. The authors state in their discussion that the pain can be explained by injury to nerves of the sacral plexus, such as the branches of the pudendal nerve. In this letter, I would like to propose that this pain can be explained by injury of the 'levator ani nerve', the nerve that lies on the superior surface of the sacrospinous ligament and in the area of the operative field. This explanation has been neglected in clinical studies so far.

Recent research by our group [2,3] and others [4-8] has emphasized that the levator ani muscle is innervated not only by the pudendal nerve from its inferior surface but also by the levator ani nerve from its superior surface. The levator ani nerve originates directly from the sacral plexus and courses on the superior surface of the coccygeus muscle/sacrospinous ligament complex towards the superior surface of the levator ani muscle (Fig. 1). On its trajectory, it crosses the sacrospinous ligament $0-4 \mathrm{~cm}$

C. Wallner $(\triangle)$

Department of Anatomy \& Embryology,

Academic Medical Center, University of Amsterdam,

Amsterdam, The Netherlands

e-mail: c.wallner@amc.uva.nl medial to the ischial spine [2,6-8]. As sutures are placed through the sacrospinous ligament approximately $2 \mathrm{~cm}$ medial to the ischial spine during sacrospinous hysteropexy or sacrospinous ligament fixation in general, the procedure can injure the levator ani nerve $[2,5-8]$ and thereby entail the sensation of buttock pain. Additional injury to the pudendal nerve may also occur because the pudendal nerve, which lies inferior to the sacrospinous ligament, is only 4-11 $\mathrm{mm}$ apart from levator ani nerve [2].

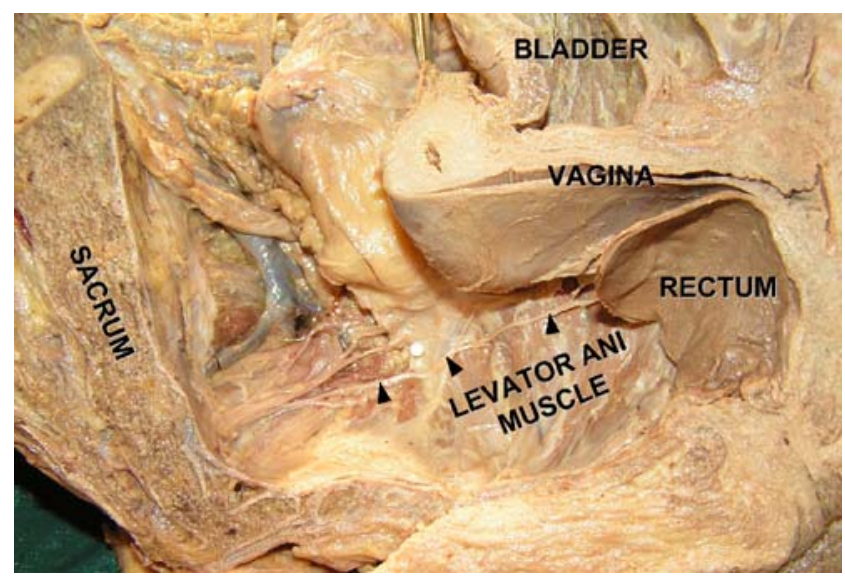

Fig. 1 The levator ani nerve $(L A N)$. Left side of a mid-sagittally transsected pelvis of an adult female cadaver. Arrowheads illustrate the course of the levator ani nerve. Note the LAN's course in the vicinity of the ischial spine (white pinhead) 
Open Access This article is distributed under the terms of the Creative Commons Attribution Noncommercial License which permits any noncommercial use, distribution, and reproduction in any medium, provided the original author(s) and source are credited.

\section{References}

1. Dietz V, Huisman M, de Jong J, Heintz P, van der Vaart C (2008) Functional outcome after sacrospinous hysteropexy for uterine descensus. Int Urogynecol J 19: 747-752 DOI 10.1007/s00192-007-520-8

2. Wallner C, Maas CP, Dabhoiwala NF, Lamers WH, DeRuiter MC (2006) The innervation of the pelvic floor muscles: a reappraisal for the levator ani nerve. Obstet Gynecol 108:529-534

3. Wallner C, van Wissen J, Maas CP, Dabhoiwala NF, DeRuiter MC, Lamers WH (2008) The contribution of the levator ani nerve and the pudendal nerve to the innervation of the levator ani muscles: a study in human fetuses. Eur Urol DOI 10.1016/j.eururo. 2007.11.015 (in press)
4. Grigorescu B, Lazarou G, Olson T, Downie S, Powers K, Greston W, Mikhail M (2007) Innervation of the levator ani muscles: description of the nerve branches to the pubococcygeus, iliococcygeus, and puborectalis muscles. Int Urogynecol J 19:107-116

5. Roshanravan SM, Wieslander CK, Schaffer JI, Corton MM (2007) Neurovascular anatomy of the sacrospinous ligament region in female cadavers: Implications in sacrospinous ligament fixation. Am J Obstet Gynecol 197:660 (e1-660.e6)

6. Takeyama M, Koyama M, Murakami G, Nagata I, Tomoe H, Furuya K (2008) Nerve preservation in tension-free vaginal mesh procedures for pelvic organ prolapse: a cadaveric study using fresh and fixed cadavers. Int Urogynecol J 19:559-566

7. Barber MD, Bremer RE, Thor KB, Dolber PC, Kuehl TJ, Coates KW (2002) Innervation of the female levator ani muscles. Am J Obstet Gynecol 187:64-71

8. Lazarou G, Grigorescu BA, Olson TR, Downie SA, Powers K, Mikhail MS (2007) Anatomic variations of the pelvic floor nerves adjacent to the sacrospinous ligament: a female cadaver study. Int Urogynecol J Pelvic Floor Dysfunct 19: 649-654 